\title{
Controversies in the Management of Functional Constipation in Children
}

\author{
M. J. van Mill ${ }^{1}$ I. J. N. Koppen ${ }^{1}$ M. A. Benninga ${ }^{1}$
}

Published online: 25 April 2019

(C) The Author(s) 2019

\begin{abstract}
Purpose of review Functional constipation (FC) in children is a common health problem with reported worldwide prevalence rates up to $32.2 \%$. The majority of children with constipation respond to oral laxative treatment. After 5 years of intensive treatment, however, approximately $50 \%$ of children remain symptomatic. To discuss the evidence for new treatments in these children, including pre- and probiotics, pelvic physiotherapy, prucalopride, sacral nerve stimulation, and surgery, and to highlight the controversies surrounding them.

Recent findings Pre- and probiotics and prucalopride are not effective in the treatment of childhood constipation. Pelvic physiotherapy and sacral nerve stimulation are promising treatment options but larger trials are needed. Surgery for pediatric constipation is the treatment of last resort.

Summary Large, well-designed placebo-controlled trials with proper outcome measures, as suggested by the Rome foundation pediatric subcommittee on clinical trials, are necessary to provide more insight regarding the efficacy of new treatments in childhood constipation.
\end{abstract}

Keywords Functional constipation · Children · Therapy $\cdot$ Surgery $\cdot$ Sacral nerve stimulation

\section{Introduction}

Functional constipation (FC) is a common problem in children, with an estimated worldwide prevalence rate of $9.5 \%$ [1]. The diagnosis of FC in children is a clinical diagnosis, which is currently based on the pediatric diagnostic Rome IV criteria [2, 3]. The Rome criteria were generated based on published evidence and through consensus among pediatric gastroenterologists and pediatric psychologists and enable healthcare professionals to better recognize and diagnose functional gastrointestinal disorders (FGIDs) (Table 1) [2, 3].

FC poses a significant burden on both children and their caregivers [4] and is associated with a reduced quality of life [5], diminished academic performances and psychological problems including aggression, anxiety, depression, and

This article is part of the Topical Collection on Large Intestine

M. A. Benninga

m.a.benninga@amc.uva.nl

1 Department of Pediatric Gastroenterology and Nutrition, Emma Children's Hospital/Amsterdam University Medical Center, Meibergdreef 9, 1105, AZ Amsterdam, The Netherlands increased emotional reactivity [6, 7]. Moreover, constipation is common in children with behavioral disorders, such as attention deficit hyperactivity disorder (ADHD) and autism spectrum disorders (ASDs) [8-10]. Symptoms of FC may persist into adulthood despite adequate laxative treatment [11].

The pathophysiology of childhood constipation is thought to be multifactorial. Genetic predisposition, low-socioeconomic status, inadequate daily fiber intake, insufficient fluid intake, and immobility have been proposed as factors leading to FC [12]. The most commonly encountered etiological factor in children is withholding behavior, usually occurring after experiencing a painful or frightening evacuation of stools [12]. Withholding behavior leads to dyssynergic defecation, incomplete evacuation of feces, fecal impaction, overflow fecal incontinence, and reduced rectal sensation.

Conventional treatment of children with FC involves nonpharmacological interventions (education, toilet training, defecation diary, and reward system) in combination with pharmacological interventions such as oral laxatives, of which polyethylene glycol (PEG) is the first-line drug of choice [13•]. Alternative treatment options for children with intractable constipation are limited and include anal sphincter botulinum toxin injections, transanal irrigation, antegrade continent enemas 
(ACE), and, in rare cases, sacral nerve stimulation (SNS) and partial or total surgical resection of the colon [14•]. This review aims to summarize the most important findings and possible controversies surrounding different treatment options for FC in children. The topics covered in this review include nonmedical interventions such as probiotics, physical therapy, new pharmacological and surgical interventions, and sacral nerve stimulation.

\section{Areas of Controversy}

\section{Diagnostics}

\section{Laboratory Testing}

Laboratory testing (e.g., for hypothyroidism, celiac disease, or hypercalcemia) in children with constipation is only indicated when there is a suspicion for an underlying organic disease. Therefore, laboratory testing does not belong in the routine workup of children with constipation without alarm symptoms [13•]. A retrospective cohort study including 7472 children with constipation showed that constipation alone did not increase the likelihood of hypothyroidism or celiac disease above the population prevalence [15]. Furthermore, no benefit of screening for hypercalcemia was found. Consequently, screening for these disorders without any suspicion of an underlying cause is associated with high healthcare costs [15-17].

\section{Abdominal X-Ray}

Evidence-based guidelines on pediatric constipation consider this entity to be a clinical diagnosis, relying on history and physical examination $[13 \bullet, 18 \bullet]$. In both pediatric and adult practice, an abdominal radiograph is frequently used as an adjunct in the management of these patients, despite the fact that the utility of this investigation is controversial $[19,20]$. Multiple prospective studies and systematic reviews do not support a diagnostic association between clinical symptoms and fecal loading on abdominal radiographs [21, 22]. More importantly, these studies showed a lack of intra- and interobserver reliability in the interpretation of plain radiographs. Lastly, relying on an abdominal radiograph for the evaluation of constipation in patients with abdominal pain frequently resulted in the wrong diagnosis or led to overlooking other diagnoses [23, 24].

Therefore, current guidelines state that a complete medical history and a thorough physical examination, including rectal examination when indicated, are usually sufficient to confirm the diagnosis in the majority of children with constipation, without exposing the child to unnecessary laboratory testing or radiation exposure $[13 \bullet, 18 \bullet]$. Abdominal X-rays are only of added value in very limited cases such as in children in whom the medical history is unreliable (e.g., patients with anorexia nervosa), if there are other psychological factors that would make rectal examination inappropriate/unreliable or too traumatic (e.g., very young and anxious children or obese children) and in children in whom there is suspicion of sexual abuse [25].

Future studies are needed to better define the role of laboratory testing and imaging for functional constipation, including whether these tests result in more effective patient management and decreases further testing. Additionally, further clarification on how radiologists should best interpret and report an abdominal X-ray is also important.

\section{Microbiome and Probiotics}

The human gut microbiome can be viewed as a dynamic organ capable of mediating a wide variety of biochemical transformations that directly impact host physiology in health and disease $[14 \bullet, 26,27 \bullet \bullet$. It has been shown that a disruption in this equilibrium can lead to alteration of host physiology resulting in functional gastrointestinal disorders including functional constipation. The role of the microbiome in FC is still uncertain. In one study, using the IS-pro, a PCR-based microbiota profiling method, applying total microbiota profiles (all phyla together) or per phylum analysis, no disease-specific separation was observed by PCOA and by calculation of diversity indices between children with FC and healthy matched controls [28]. By ridge regression, however, FC and controls could be discriminated with $82 \%$ accuracy. Most discriminative species were Bacteroides fragilis, Bacteroides ovatus, Bifidobacterium longum, Parabacteroides species (increased in functional constipation) and Alistipes finegoldii (decreased in FC) [28]. In contrast, taxonomic profiling of the fecal microbiome from adults with FC and healthy volunteers showed a decreased abundance of Bacteroides, Roseburia, and Coprococcus [27••]. Furthermore, healthy volunteers were found to have a gut microbiome enriched in genes involved in carbohydrate, fatty acid, and lipid metabolism whereas FC patients harbored a high abundance of genes involved in methanogenic pathways, hydrogen production, and glycerol [27••]. Optimization of microbiota-based interventions in constipated patients warrants further characterization of microbial signatures linked to clinical subgroups of FC.

A recent systematic review evaluating the effect of probiotics in infants and children with FC included seven RCTs with a total of 515 constipated children [29]. The included trials were heterogeneous with respect to study population, probiotic strains, dosages, study duration, and followup. In this review, the available studies were not able to demonstrate a significant difference between the probiotic and control groups with respect to treatment success. While some probiotic strains showed some effects on defecation 
Table 1 Rome IV criteria functional obstipation $[2,3]$

Children $<4$ years*

(1) 2 or fewer defecations per week

(2) History of excessive stool retention

(3) History of painful or hard bowel movements

(4) History of large-diameter stools

(5) Presence of a large fecal mass in the rectum

In toilet-trained children, the following additional criteria may be used:

(1) At least 1 episode/week of incontinence after the acquisition of toileting skills

(2) History of large-diameter stools that may obstruct the toilet
Children $>4$ years ${ }^{* *}$

(1) 2 or fewer defecations in the toilet per week in a child of a developmental age of at least 4 years

(2) At least 1 episode of fecal incontinence per week

(3) History of retentive posturing or excessive volitional stool retention

(4) History of painful or hard bowel movements

(5) Presence of a large fecal mass in the rectum

(6) History of large-diameter stools that can obstruct the toilet

*Must fulfill $\geq 2$ criteria at least once per week for a minimum of 1 month with insufficient criteria for a diagnosis of irritable bowel syndrome

**Must fulfill $\geq 2$ criteria at least once per week for a minimum of 1 month with insufficient criteria for a diagnosis of irritable bowel syndrome. After appropriate evaluation, the symptoms cannot be fully explained by another medical condition

frequency, none of the probiotics had beneficial effects on the frequency of fecal incontinence or frequency of abdominal pain. Adverse events were rare and not serious. Based on these data, there is currently insufficient evidence to support the use of probiotics in children with FC.

\section{Fibers}

Significant progress in microbiome science has not only discovered the functional impact of dietary fiber on the composition and function of the microbiota but also showed the physiologic responses to microbial-derived metabolites from fiber digestion [30••]. Oligosaccharides (fructo-oligosaccharides (FOS) and galacto-oligosaccharides (GOS), soluble, nonviscous, readily fermentable fibers (inulin, wheat dextrin), soluble, viscous fibers ( $\beta$-glucan, gums, pectin, psyllium) do not undergo extensive fermentation and are able to interact with water allowing softening of stools [30••]. Insoluble fibers (wheat bran, lignin, cellulose) exert a laxative effect by stimulation and irritation of gut mucosa to increase secretion and peristalsis $[30 \bullet \bullet$.

Several studies have demonstrated that children consume a low intake of dietary fiber, due to limited ingestion of vegetables, fruits, and whole grains, and are more prone to develop constipation [31,32]. With the help of a dedicated dietician, it is possible to significantly increase fiber intake in children with FC and for at least 6 months [33, 34]. Disappointingly, however, no significant benefit has been demonstrated in terms of reduction in laxative use or increased stool frequency associated with additional fiber intake in children. Moreover, a recent systematic review including 680 children with FC showed no significant improvement after additional fiber intake with respect to defecation parameters, fecal incontinence episodes, abdominal pain, and treatment success [35]. The studies were of low quality and the methods used varied considerably with different definitions of constipation, different fibers, and different outcome measures. Therefore, based on the current literature, there is little evidence to support the administration of fiber supplements in children with FC with already normal fiber intake.

\section{Pharmacological Treatment}

When non-pharmacological interventions fail to improve symptoms of pediatric FC, pharmacological treatment with laxatives is indicated $\left[13^{\bullet}, 18^{\bullet}\right]$. Firstly, treatment is aimed at disimpaction to remove any fecal masses. This is achieved through either rectally administered enemas or temporary high-dose oral polyethylene glycol (PEG). Subsequently, maintenance therapy with PEG should be initiated to prevent re-accumulation of feces. Lastly, after at least a 2-month period of symptom relief, maintenance therapy should be gradually weaned to prevent a relapse. To date, PEG is the laxative of the first choice for both disimpaction (high dose 1-1.5 g/kg/ day) and maintenance treatment $(0.2-0.8 \mathrm{~g} / \mathrm{kg} /$ day) [36]. Over the past few years, the FDA has received reports of tremors, tics, and obsessive-compulsive behavior in children taking PEG 3350, which has caused worries among patients and caregivers and has led to the initiation of an investigation by the FDA [37]. Whether there is truly a causal relationship between the use of PEG, these events is still under investigation and causality has not been established. Therefore, the FDA has decided that no action is necessary at this time based on available information [37]. One hypothesis behind the potential association is that PEG 3350 might contain trace amounts of ethylene glycol (EG), diethylene glycol (DEG), and triethylene glycol (TEG), which in high concentrations can be neurotoxic [38, 39]. 
However, a recent study showed that daily PEG 3350 therapy in children with FC was not associated with sustained elevation of EG, DEG, or TEG blood levels over levels in matched controls and peak values remained well below toxic levels [7].

Besides PEG, several other osmotic laxatives such as lactulose, lactitol, and magnesium hydroxide are available, but studies have shown a lower efficacy than PEG for all of these agents. Stimulant laxatives, such as diphenylmethanes (e.g., bisacodyl) and anthraquinones (e.g., senna) are often used for short periods of time and are associated with more side effects such as abdominal pain [13•, 18•].

Based on the available evidence, PEG is recommended as the treatment of the first choice in children with FC $[13 \bullet, 18 \bullet]$. Studies performed to evaluate the efficacy for the use of other commonly used drugs in children with FC are scarce and often of low quality [36]. Outcome measures and definitions of treatment success vary greatly between studies, which make it difficult to compare the results of these studies. In order to overcome these limitations, a Rome working committee recently published recommendations for the design of pharmacological clinical trials for FC in childhood [40•]. The working group recommends conducting randomized, double-blind, placebo-controlled, parallel group clinical trials to assess the efficacy of new drugs for the treatment of childhood FC and gave specific recommendations on outcomes to use and on the duration of follow-up. With these recommendations, future research will, hopefully, enable better comparison of pharmacological treatments of FC in children.

\section{Novel Pharmacological Therapies}

In recent years, several novel therapeutic agents have been investigated in the treatment of FC among these are lubiprostone and prucalopride. Although pilot studies in children and RCTs in adults have rendered positive results, large multicenter RCTs have not provided sufficient evidence to incorporate these compounds into the routine care of children with FC.

Lubiprostone stimulates the secretion of chloride-rich fluid in the intestine, thereby softening stools and enhancing stool volume. A pilot study has suggested that lubiprostone significantly increased bowel movements and that it was well tolerated in children with FC [41]. This has led to a multicenter RCT in children with FC which was recently completed, but the results of this study have not yet been published.

Prucalopride is a selective, $5-\mathrm{HT}_{4}$ receptor agonist that enhances motility in the gastrointestinal tract. In an open-label pilot study, prucalopride had a favorable effect on stool frequency, stool consistency, and fecal incontinence frequency in children with FC [42]. However, in a multicenter RCT, including 200 children with FC, prucalopride was not more effective in increasing stool frequency or decreasing fecal incontinence frequency compared to placebo [43•].

\section{Nonpharmacological Therapies}

\section{Biofeedback/Physical Therapy}

Dyssynergic defecation referring to pelvic floor dysfunction is considered to play a role in the development of constipation in children. Biofeedback therapy and pelvic physiotherapy are potential treatment options to correct this abnormal defecation behavior [44, 45]. A systematic review evaluated the effect of biofeedback therapy in adults and children with constipation and concluded that biofeedback therapy is effective for the short-term and long-term treatment of adults with constipation with dyssynergic defecation, but showed a lack of evidence to support the use of biofeedback therapy for the treatment of childhood constipation [44].

However, four recent studies, of which two were uncontrolled, showed beneficial effects of pelvic physiotherapy in children with FC or in children with functional or organic causes of fecal incontinence [45-48]. The multicenter RCT by van Engelenburg et al. comparing standard medical (education, toilet training, and laxatives) (SMC) with pelvic physiotherapy (PPT) in addition to standard medical care showed that PPT was effective for $92.3 \%$ of the children and for $63 \%$ of the children receiving SMC [48]. However, this latter study included only 53 of the targeted 367 children, so their findings need to be interpreted with caution [49]. Even if the significant effect found in this study was not a false-positive result, it is possible that the estimate of the magnitude of the effect was exaggerated (winner's curse) [49].

It is unclear why biofeedback therapy given by medical doctors is less effective than PPT. Physiotherapists state that they are musculoskeletal experts and that therefore the approach in children with FC differs from biofeedback therapy. PPT uses motor relearning programs of deliberate and repeated practice to achieve cure: (1) supporting toilet training (balance and core stability, posture, breathing exercises, relaxing of the body, and effective straining); (2) increasing awareness of sensations as urge (sensory processing techniques, such as filtering, organizing, integrating sensory information, and rectal balloon training); and (3) pelvic floor muscles training (awareness, relaxing during defecation, or, in contrast, contracting to prevent FI, and when needed to be supported by myofeedback or rectal balloon training) [48]. A recent RCT in children with FC referred for PPT by primary care doctors was confronted with an unforeseen recruitment problem, since many children and their parents refused randomization because PPT was considered too burdensome [50]. Before we can recommend PPT as an effective treatment in childhood FC, we need larger studies. 


\section{Neuromodulation}

Sacral nerve stimulation (SNS) involves low-amplitude electrical stimulation of the sacral nerve via an electrode placed through the sacral foramen $[51,52]$. In adults, SNS as a treatment option for defecatory symptoms (including constipation) has been under investigation for more than two decades [51]. In the first study on SNS treatment for children with FC, symptomatic improvement was found in 12 female adolescents with FC at up to 12 months of follow-up [53]. In a follow-up study that included the group originally described by van Wunnik et al., significant symptomatic improvement was reported in 27 female children and adolescents with FC who had been treated with SNS for 12-37 months [54]. Although the response to SNS was not uniform in this cohort, SNS did appear to provide sustained benefit for children with FC refractory to conventional treatment. At a different center, short-term outcomes were reported for 29 children treated with SNS, including 22 children who had constipation of different origins [55]. A significant improvement in symptoms and quality of life was reported at a median of 4-5 months after SNS initiation. In a follow-up study, SNS led to continued improvement in both symptoms and quality of life at 2 years after treatment initiation, with particular improvement in concurrent fecal incontinence [56]. At follow-up, $68 \%$ of patients fulfilled the predefined criteria for successful response and $24 \%$ fulfilled criteria without concurrent laxative or ACE use.

A different method of neuromodulation is interferential electrical stimulation on the abdominal wall and pelvic floor $[57 \bullet \bullet, 58]$. Interferential electrical stimulation is a noninvasive procedure and can be performed by physiotherapists and at home by parents [59]. A single-center, double-blind randomized clinical trial investigating the additional effect of interferential electrical stimulation on pelvic floor muscle exercises (PFM) in 90 children with FC showed that PFM was significantly more effective compared to sham PFM (84.4\% vs $43.2 \%$ ) [60]. The positive effects were sustained after 6 months of follow-up. Reported side effects of interferential electrical stimulation were minimal and included discomfort during the treatment. Given the non-invasive character of the treatment, this is a promising finding with a need for further research.

\section{Surgical Interventions}

In severe cases of intractable $\mathrm{FC}$, surgical treatment is sometimes considered as a treatment of last resort [61•]. A survey study showed that physicians differ in surgical decisionmaking for children with intractable FC [62]. Given the difficulties involved in decision-making and the high impact of surgical interventions, there is a great need for consensus guidelines for surgical interventions in childhood FC
[62]. Two publications have currently attempted to provide such a protocol based on literature review and clinical experience $[61 \bullet, 63]$. Unfortunately, most published studies are small and have observational study designs.

Several surgical procedures have been described in the treatment of FC in children, including procedures focused at the pelvic floor (anal botulinum injections, anal dilation, and anal myectomy) and procedures focused at the large bowel (ACE, colostomy, and colonic resection) [61•]. Although studies are small and scarce, some studies have shown that injection of botulinum toxin into the internal or external anal sphincter can be an effective treatment for patients with FC [64-66]. Botulinum toxin causes temporary chemical paralysis of smooth and striated muscle fibers by blocking the release of acetylcholine from neurons, which cause the sphincter muscles to relax. However, botulinum toxin is an expensive treatment, requires general anesthesia, and the effect is only temporary, usually lasting for 3 to 6 months. Sometimes, repeated injections are administered after the initial effect wears off. Anal myectomy and anal dilation have been largely abandoned by surgeons due to the risk of complications. The major risk of these two procedures is that the basal pressure of the anal sphincter can be weakened to the point of causing fecal incontinence [62].

Currently, surgery of the colon is based on an extensive diagnostic workup including motility testing, often evaluated with colonic manometry. If colonic dysmotility is present, bypassing or removing the dysmotile colonic segment has been shown to be favorable for FC symptoms [67]. However, it has also been shown that dysmotility is potentially reversible and that motility, as measured by colonic manometry, can improve after decompression of the colon or after successful antegrade irrigation [68-71]. This suggests that colonic dysmotility may not only contribute to the etiology of FC but may also be a consequence of longstanding FC, possibly because of fecal stasis leading to suboptimal colonic motor function. Whether diversion is better than resection is currently not clear. Some centers have suggested to combine ACE with resection and have shown positive results [72]. Future studies comparing different surgical strategies are needed to clarify which approach renders the best results.

Although the efficacy of various invasive surgical procedures has been reported to be quite high, various surgeryrelated complications have been reported $[61 \cdot, 67]$. Surgery for $\mathrm{FC}$ requires a specialized team of pediatric gastroenterologists, pediatric surgeons, specialized stoma nurses, and child psychologists and is therefore best performed at specialized centers. Before surgical interventions are considered in these patients, families should be counseled by this type of multidisciplinary team which should include a psychological evaluation and if necessary, a psychiatric evaluation. Patients and their families should be thoroughly 
educated about the prognosis of the procedure they are about to undergo. Despite the high complication rate for some procedures, parents have been reported to be very satisfied with the final outcome [67].

\section{Conclusion}

Functional constipation is a common healthcare problem in children and has an important impact on a child's life. In the majority of children with FC, extensive research has shown that laboratory testing or abdominal X-rays are unnecessary for diagnosing FC. A combination of education, toilet training, and an early start of laxative treatment, lasting for at least 2 months, is effective in the majority of children with FC. Currently, there is insufficient evidence to support the use of prebiotics, probiotics, and synbiotics in the treatment of these children.

In clinical practice, it remains a challenge, however, to improve the outcomes of children with intractable FC symptoms. New compounds such as lubiprostone, prucalopride, and linaclotide have shown to be effective in adults, but these drugs are either not effective or have not yet been evaluated in large randomized controlled trials in children with FC. Large, well-designed placebo-controlled trials with proper outcome measures, as suggested by the Rome foundation pediatric subcommittee on clinical trials, are necessary to provide more insight regarding the efficacy of these new compounds.

Of the current new non-pharmacological treatments for childhood constipation, PPT and neuromodulation have shown promise. In line with the recommendations to test new pharmacological treatments, large randomized controlled trials are necessary to establish their true value in the treatment of children with FC. In children with longlasting symptoms of FC, such as infrequent painful stools in combination with fecal incontinence, and in whom both old and new oral and rectal therapies fail, surgery may be the treatment of last resort. Together with an experienced multidisciplinary team, the possible benefits of surgical interventions should be balanced against the risks of complications and stoma problems.

\section{Compliance with Ethical Standards}

Conflict of Interest M. Benninga is a consultant and PI for Shire, Norgine, Takeda, Coloplast, Allergan, Mead Johnson, Danone, Freisland Campina, and Novalac. Honoraria is paid to his hospital.

M.J. van Mill and I.J.N. Koppen declare no conflict of interest.

Human and Animal Rights and Informed Consent This article does not contain any studies with human or animal subjects performed by any of the authors.
Open Access This article is distributed under the terms of the Creative Commons Attribution 4.0 International License (http:// creativecommons.org/licenses/by/4.0/), which permits unrestricted use, distribution, and reproduction in any medium, provided you give appropriate credit to the original author(s) and the source, provide a link to the Creative Commons license, and indicate if changes were made.

\section{References}

Papers of particular interest, published recently, have been highlighted as:

- Of importance

•. Of major importance

1. Koppen IJ, Vriesman MH, Saps M, Rajindrajith S, Shi X, van Etten-Jamaludin FS, et al. Prevalence of functional defecation disorders in children: a systematic review and meta-analysis. J Pediatr. 2018;198:121-30 E6.

2. Benninga MA, Faure C, Hyman PE, St James Roberts I, Schechter NL, Nurko S. Childhood functional gastrointestinal disorders: neonate/toddler. Gastroenterology. 2016;150(6):1443-55.

3. Hyams JS, Di Lorenzo C, Saps M, Shulman RJ, Staiano A, van Tilburg M. Functional disorders: children and adolescents. Gastroenterology. 2016;150(6):1456-68.

4. Kaugars AS, Silverman A, Kinservik M, Heinze S, Reinemann L, Sander M, et al. Families'perspectives on the effect of constipation and fecal incontinence on quality of life. J Pediatr Gastroenterol Nutr. 2010;51(6):747-52.

5. Kovacic K, Sood MR, Mugie S, Di Lorenzo C, Nurko S, Heinz N, et al. A multicenter study on childhood constipation and fecal incontinence: effects on quality of life. J Pediatr. 2015;166(6):14827.

6. Joinson C, Heron J, Butler U, von Gontard A. Psychological differences between children with and without soiling problems. Pediatrics. 2006;117(5):1575-84.

7. Williams KC, Rogers LK, Hill I, Barnard J, Di Lorenzo C. PEG 3350 administration is not associated with sustained elevation of glycol levels. J Pediatr. 2018;195:148-53.e1.

8. Peeters B, Noens I, Philips EM, Kuppens S, Benninga MA. Autism spectrum disorders in children with functional defecation disorders. J Pediatr. 2013;163(3):873-8.

9. Kuizenga-Wessel S, Koppen IJN, Vriesman MH, Di Lorenzo C, van Dijk M, Beelen MLR, et al. Attention deficit hyperactivity disorder and functional defecation disorders in children. J Pediatr Gastroenterol Nutr. 2018;66(2):244-9.

10. Kuizenga-Wessel S, Di Lorenzo C, Nicholson LM, Butter EM, Ratliff-Schaub KL, Benninga MA, et al. Screening for autism identifies behavioral disorders in children functional defecation disorders. Eur J Pediatr. 2016;175(10):1371-8.

11. Bongers ME, van Wijk MP, Reitsma JB, Benninga MA. Long-term prognosis for childhood constipation: clinical outcomes in adulthood. Pediatrics. 2010;126(1):e156-62.

12. Mugie SM, Di Lorenzo C, Benninga MA. Constipation in childhood. Nat Rev Gastroenterol Hepatol. 2011;8(9):502-11.

13. Tabbers MM, DiLorenzo C, Berger MY, Faure C, Langendam MW, Nurko S, et al. Evaluation and treatment of functional constipation in infants and children: evidence-based recommendations from ESPGHAN and NASPGHAN. J Pediatr Gastroenterol Nutr. 2014;58(2):258-74 Summary information and guideline on diagnosis and treatment of functional constipation in children. 
14. Koppen IJ, Di Lorenzo C, Saps M, Dinning PG, Yacob D, Levitt MA, et al. Childhood constipation: finally something is moving! Expert Rev Gastroenterol Hepatol. 2016;10(1):141-55 Latest update on new diagnostics and treatment of functional constipation in children.

15. Chogle A, Saps M. Yield and cost of performing screening tests for constipation in children. Can J Gastroenterol. 2013;27(12):e35-8.

16. Liem O, Harman J, Benninga M, Kelleher K, Mousa H, Di Lorenzo C. Health utilization and cost impact of childhood constipation in the United States. J Pediatr. 2009 Feb;154(2):258-62.

17. Choung RS, Shah ND, Chitkara D, Branda ME, Van Tilburg MA, Whitehead WE, et al. Direct medical costs of constipation from childhood to early adulthood: a population-based birth cohort study. J Pediatr Gastroenterol Nutr. 2011;52(1):47-54.

18. Bardisa-Ezcurra L, Ullman R, Gordon J. Diagnosis and management of idiopathic childhood constipation: summary of NICE guidance. Guideline development group. BMJ. 2010;1:340 Summary information and guideline on diagnosis and treatment of functional constipation in children.

19. Beinvogl B, Sabharwal S, McSweeney M, Nurko S. Are we using abdominal radiographs appropriately in the management of pediatric constipation? J Pediatr. 2017;191:179-83.

20. Reber J, McGauvran A, Froemming A. Abdominal radiograph usage trends in the setting of constipation: a 10-year experience. Abdom Radiol (NY). 2018;43(9):2231-8.

21. Pensabene L, Buonomo C, Fishman L, Chitkara D, Nurko S. Lack of utility of abdominal x-rays in the evaluation of children with constipation: comparison of different scoring methods. J Pediatr Gastroenterol Nutr. 2010;51(2):155-9.

22. Berger MY, Tabbers MM, Kurver MJ, Boluyt N, Benninga MA. Value of abdominal radiography, colonic transit time, and rectal ultrasound scanning in the diagnosis of idiopathic constipation in children: a systematic review. J Pediatr. 2012;161(1):44-50.

23. Freedman SB, Thull-Freedman J, Manson D, Rowe MF, Rumantir $\mathrm{M}$, Eltorki M, et al. Pediatric abdominal radiograph use, constipation, and significant misdiagnoses. J Pediatr. 2014;164(1):83-8.

24. Petinaux B, Bhat R, Boniface K, Aristizabal J. Accuracy of radiographic readings in the emergency department. Am J Emerg Med. 2011;29(1):18-25.

25. Benninga MA, Tabbers MM, van Rijn RR. How to use a plain abdominal radiograph in children with functional defecation disorders. Arch Dis Child Educ Pract Ed. 2016;101(4):187-93.

26. Johnson CL, Versalovic J. The human microbiome and its potential importance to pediatrics. Pediatrics. 2012;129(5):950-60.

27.• Shin A, Preidis GA, Shulman R, Kashyap PC. The gut microbiome in adult and pediatric functional gastrointestinal disorders. Clin Gastroenterol Hepatol. 2019;17(2):256-74 A pivotal review on the microbiome in FGIDs.

28. de Meij TG, de Groot EF, Eck A, Budding AE, Kneepkens CM, Benninga MA, et al. Characterization of microbiota in children with chronic functional constipation. PLoS One. 2016;11(10):e0164731.

29. Wojtyniak K, Szajewska H. Systematic review: probiotics for functional constipation in children. Eur J Pediatr. 2017;176(9):1155-62.

30.• O'Grady J, O'Connor EM, Shanahan F. Review article: dietary fibre in the era of microbiome science. Aliment Pharmacol Ther. 2019;49(5):506-15 A pivotal review on fibers.

31. Morais MB, Vitolo MR, Aguirre AN, Fagundes-Neto U. Measurement of low dietary fiber intake as a risk factor for chronic constipation in children. J Pediatr Gastroenterol Nutr. 1999;29(2): 132-5.

32. Butte NF, Fox MK, Briefel RR, Siega-Riz AM, Dwyer JT, Deming DM, et al. Nutrient intakes of US infants, toddlers, and preschoolers meet or exceed dietary reference intakes. J Am Diet Assoc. 2010;110(Suppl. 12):S27-37.

33. Sullivan PB, Alder N, Shrestha B, Turton L, Lambert B. Effectiveness of using a behavioural intervention to improve dietary fibre intakes in children with constipation. J Hum Nutr Diet. 2012;25(1):33-42.

34. Karagiozoglou-Lampoudi T, Daskalou E, Agakidis C, Savvidou A, Apostolou A, Vlahavas G. Personalized diet management can optimize compliance to a high-fiber, high-water diet in children with refractory functional constipation. J Acad Nutr Diet. 2012;112(5): 725-9.

35. Piccoli de Mello P, Eifer DA, Daniel de Mello E. Use of fibers in childhood constipation treatment: systematic review with metaanalysis. J Pediatr. 2018;94(5):460-70.

36. Koppen IJ, Lammers LA, Benninga MA, Tabbers MM. Management of functional constipation in children: therapy in practice. Paediatr Drugs. 2015;17(5):349-60.

37. Koppen IJN, Broekaert IJ, Wilschanski M, Papadopoulou A, RibesKoninckx C, Thapar N, et al. Role of polyethylene glycol in the treatment of functional constipation in children. J Pediatr Gastroenterol Nutr. 2017;65(4):361-3.

38. Brent J. Current management of ethylene glycol poisoning. Drugs. 2001;61:979-88.

39. Schep LJ, Slaughter RJ, Temple WA, Beasley DM. Diethylene glycol poisoning. Clin Toxicol (Phila). 2009;47(6):525-35.

40. Koppen IJN, Saps M, Lavigne JV, et al. Recommendations for pharmacological clinical trials in children with functional constipation: the Rome foundation pediatric subcommittee on clinical trials. Neurogastroenterol Motil. 2018;30:e13294 Recommendations how to perform clinical trials in children with constipation.

41. Hyman PE, Di Lorenzo C, Prestridge LL, Youssef NN, Ueno R. Lubiprostone for the treatment of functional constipation in children. J Pediatr Gastroenterol Nutr. 2014;58(3):283-91.

42. Winter HS, Di Lorenzo C, Benninga MA, Gilger MA, Kearns GL, Hyman PE, et al. Oral prucalopride in children with functional constipation. J Pediatr Gastroenterol Nutr. 2013;57(2):197-203.

43. Mugie SM, Korczowski B, Bodi P, Green A, Kerstens R, Ausma J, et al. Prucalopride is no more effective than placebo for children with functional constipation. Gastroenterology. 2014;147(6):128595 Pivotal study of prucalopride in pediatric constipation.

44. Rao SS, Benninga MA, Bharucha AE, Chiarioni G, Di Lorenzo C, Whitehead WE. ANMS-ESNM position paper and consensus guidelines on biofeedback therapy for anorectal disorders. Neurogastroenterol Motil. 2015;27(5):594-609.

45. Muddasani S, Moe A, Semmelrock C, Gilbert CL, Enemuo V, Chiou EH, et al. Physical therapy for fecal incontinence in children with pelvic floor dyssynergia. J Pediatr. 2017;190:74-8.

46. Silva CA, Motta ME. The use of abdominal muscle training, breathing exercises and abdominal massage to treat paediatric chronic functional constipation. Color Dis. 2013;15:e250-5.

47. Abedi A, Esmaeil-Dooki MR, Jalilian R, Tabari SM. Pelvic floor muscle exercise for paediatric functional constipation. J Clin Diagn Res. 2015;9(6):SC16-7.

48. van Engelenburg-van Lonkhuyzen ML, Bols EM, Benninga MA, Verwijs WA, de Bie RA. Effectiveness of pelvic physiotherapy in children with functional constipation compared with standard medical care. Gastroenterology. 2017;152(1):82-91.

49. van Summeren J, Dekker J, Berger M. Pelvic physiotherapy in children with functional constipation: promising but more research needed. Gastroenterology. 2017;152(8):2080-1.

50. van Summeren JJGT, Holtman GA, Lisman-van Leeuwen Y, Louer LEAM, van Ulsen-Rust AHC, et al. Physiotherapy plus conventional treatment versus conventional treatment only in the treatment of functional constipation in children: design of a randomized controlled trial and cost-effectiveness study in primary care. BMC Pediatr. 2018;18(1):249.

51. Thaha MA, Abukar AA, Thin NN, Ramsanahie A, Knowles CH. Sacral nerve stimulation for faecal incontinence and constipation in adults. Cochrane Database Syst Rev. 2015;8:CD004464. 
52. Iacona R, Ramage L, Malakounides G. Current state of neuromodulation for constipation and fecal incontinence in children: a systematic review. Eur J Pediatr Surg. 2019.

53. van Wunnik BP, Peeters B, Govaert B, Nieman FH, Benninga MA, Baeten CG. Sacral neuromodulation therapy: a promising treatment for adolescents with refractory functional constipation. Dis Colon Rectum. 2012;55(3):278-85.

54. van der Wilt AA, van Wunnik BPW, Sturkenboom R, Han-Geurts IJ, Melenhorst J, Benninga MA, et al. Sacral neuromodulation in children and adolescents with chronic constipation refractory to conservative treatment. Int J Color Dis. 2016;31(8):1459-66.

55. Sulkowski JP, Nacion KM, Deans KJ, Minneci PC, Levitt MA, Mousa HM, et al. Sacral nerve stimulation: a promising therapy for fecal and urinary incontinence and constipation in children. $\mathrm{J}$ Pediatr Surg. 2015;50(10):1644-7.

56. Lu PL, Koppen IJ, Orsagh-Yentis DK, Leonhart K, Ambeba EJ, Deans KJ, et al. Sacral nerve stimulation for constipation and fecal incontinence in children: long-term outcomes, patient benefit, and parent satisfaction. Neurogastroenterol Motil. 2018;30(2):e13184.

57.• Payne SC, Furness JB, Stebbing MJ. Bioelectric neuromodulation for gastrointestinal disorders: effectiveness and mechanisms. Nat Rev Gastroenterol Hepatol. 2019;16(2):89-105 Pivotal review on neuromodulation for gastrointestinal disorders.

58. Hutson JM, Dughetti L, Stathopoulos L, Southwell BR. Transabdominal electrical stimulation (TES) for the treatment of slow-transit constipation (STC). Pediatr Surg Int. 2015;31(5):44551.

59. Yik YI, Stathopoulos L, Hutson JM, Southwell BR. Home transcutaneous electrical stimulation therapy to treat children with anorectal retention: a pilot study. Neuromodulation. 2016;19(5): $515-21$.

60. Sharifi-Rad L, Ladi-Seyedian SS, Manouchehri N, Alimadadi H, Allahverdi B, Motamed F, et al. Effects of interferential electrical stimulation plus pelvic floor muscles exercises on functional constipation in children: a randomized clinical trial. Am J Gastroenterol. 2018;113(2):295-302.

61. Siminas S, Losty PD. Current surgical management of pediatric idiopathic constipation: a systematic review of published studies. Ann Surg. 2015;262(6):925-33 Review describing the different surgical interventions for pediatric constipation.

62. Koppen IJ, Kuizenga-Wessel S, Lu PL, Benninga MA, Di Lorenzo $\mathrm{C}$, Lane VA, et al. Surgical decision-making in the management of children with intractable functional constipation: what are we doing and are we doing it right? J Pediatr Surg. 2016;51(10):1607-12.
63. Wood RJ, Yacob D, Levitt MA. Surgical options for the management of severe functional constipation in children. Curr Opin Pediatr. 2016;28(3):370-9.

64. Keshtgar AS, Ward HC, Sanei A, Clayden GS. Botulinum toxin, a new treatment modality for chronic idiopathic constipation in children: long-term follow-up of a doubleblind randomized trial. J Pediatr Surg. 2007;42(4):672-80.

65. Chumpitazi BP, Fishman SJ, Nurko S. Long-term clinical outcome after botulinum toxin injection in children with nonrelaxing internal anal sphincter. Am J Gastroenterol. 2009;104(4):976-83.

66. Zar-Kessler C, Kuo B, Belkind-Gerson J. Botulinum toxin injection for childhood constipation is safe and can be effective regardless of anal sphincter dynamics. J Pediatr Surg. 2018;53(4):693-7.

67. Kuizenga-Wessel S, Koppen IJ, Zwager LW, Di Lorenzo C, de Jong JR, Benninga MA. Surgical management of children with intractable functional constipation; experience of a single tertiary children's hospital. Neurogastroenterol Motil. 2017;29(5):e13005.

68. Villarreal J, Sood M, Zangen T, Flores A, Michel R, Reddy N, et al. Colonic diversion for intractable constipation in children: colonic manometry helps guide clinical decisions. J Pediatr Gastroenterol Nutr. 2001;33(5):588-91.

69. Christison-Lagay ER, Rodriguez L, Kurtz M, St Pierre K, Doody DP, Goldstein AM. Antegrade colonic enemas and intestinal diversion are highly effective in the management of children with intractable constipation. J Pediatr Surg. 2010;45(1):213-9.

70. Martin MJ, Steele SR, Noel JM, Weichmann D, Azarow KS. Total colonic /manometry as a guide for surgical management of functional colonic obstruction: preliminary results. J Pediatr Surg. 2001;36(12):1757-63.

71. Rodriguez L, Nurko S, Flores A. Factors associated with successful decrease and discontinuation of antegrade continence enemas (ACE) in children with defecation disorders: a study evaluating the effect of ACE on colon motility. Neurogastroenterol Motil. 2013;25(2):140-e81.

72. Gasior A, Reck C, Vilanova-Sanchez A, Diefenbach KA, Yacob D, $\mathrm{Lu} \mathrm{P}$, et al. Surgical management of functional constipation: an intermediate report of a new approach using a laparoscopic sigmoid resection combined with Malone appendicostomy. J Pediatr Surg. 2018;53(6):1160-2

Publisher's Note Springer Nature remains neutral with regard to jurisdictional claims in published maps and institutional affiliations. 